\title{
Article \\ Factors Related to Diet Quality: A Cross-Sectional Study of 1055 University Students
}

\author{
Enrique Ramón-Arbués ${ }^{1,2} \oplus$, José-Manuel Granada-López 2,3,4®, Blanca Martínez-Abadía 5 , \\ Emmanuel Echániz-Serrano ${ }^{2,3}\left(\mathbb{D}\right.$, Isabel Antón-Solanas ${ }^{3,6, *} *$ and Benjamin Adam Jerue ${ }^{7}$ \\ 1 Faculty of Health Sciences, Campus Universitario Villanueva de Gállego, Universidad San Jorge, \\ Villanueva de Gállego, 50830 Zaragoza, Spain; eramon@usj.es \\ 2 Research Group Transfercult (H27_20D), University of Zaragoza, 50009 Zaragoza, Spain; \\ jmgranada@unizar.es (J.-M.G.-L.); eechaniz@unizar.es (E.E.-S.) \\ 3 Department of Physiatrics and Nursing, Faculty of Health Sciences, University of Zaragoza, \\ C/Domingo Miral S/N, 50009 Zaragoza, Spain \\ 4 Research Group Safety and Care (GIISA021), Institute of Research of Aragón, 50009 Zaragoza, Spain \\ 5 Occupational Health and Prevention Service, Zaragoza City Council, $P^{\circ}$ de La Mina 9, 50001 Zaragoza, Spain; \\ bmartinez@zaragoza.es \\ 6 Research Group Nursing Research in Primary Care in Aragón (GENIAPA) (GIIS094), Institute of Research of Aragón, \\ 50009 Zaragoza, Spain \\ 7 Faculty of Communication and Social Sciences, Campus Universitario Villanueva de Gállego, \\ Universidad San Jorge, Villanueva de Gállego, 50830 Zaragoza, Spain; bajerue@usj.es \\ * Correspondence: ianton@unizar.es
}

\section{check for} updates

Citation: Ramón-Arbués, E.; Granada-López, J.-M.;

Martínez-Abadía, B.;

Echániz-Serrano, E.; Antón-Solanas,

I.; Jerue, B.A. Factors Related to Diet Quality: A Cross-Sectional Study of 1055 University Students. Nutrients 2021, 13, 3512. https://doi.org/ $10.3390 /$ nu13103512

Academic Editors: Clare Collins and George Moschonis

Received: 30 August 2021

Accepted: 1 October 2021

Published: 5 October 2021

Publisher's Note: MDPI stays neutral with regard to jurisdictional claims in published maps and institutional affiliations.

Copyright: (c) 2021 by the authors. Licensee MDPI, Basel, Switzerland. This article is an open access article distributed under the terms and conditions of the Creative Commons Attribution (CC BY) license (https:// creativecommons.org/licenses/by/ $4.0 /)$.
Abstract: Given that there is only a limited body of evidence available concerning the dietary habits of Spanish university students, the present study assesses the quality of this group's diet, their adherence to the National Food-Based Dietary Guidelines, and the predictive factors of their diet quality. To do so, a cross-sectional study was performed on a sample of 1055 students. The quality of the participants' diets was then analysed by using the Spanish Healthy Eating Index, and then their level of compliance was assessed in light of the dietary recommendations put forth by the Spanish Society for Community Nutrition. According to these standards, only $17.4 \%$ of the participants had a healthy diet. The level of compliance with the recommendations was poor, highlighting especially the low levels of "fruit" and "vegetables" that they consumed as well as high levels of "cold meats and cuts" and "sweets". The factors that predicted a worse diet are being male, living alone, low levels of physical activity, smoking, high alcohol intake, leading a sedentary lifestyle, psychological distress, and insomnia $(p<0.005)$. Furthermore, participants with low or high body weights showed signs of a higher quality diet $(p<0.001)$. The present findings suggest that a significant proportion of university students ought to change their dietary habits; these also attest to the importance of developing strategies that are directly targeted at university students in order to promote a healthy diet.

Keywords: diet quality; dietary guidelines; university students; cross-sectional study

\section{Introduction}

Research has repeatedly shown the important role that diet plays in maintaining one's short and long-term health as well as its relation to life expectancy [1,2]. Accordingly, increasing diet quality could be independently associated with a reduced risk of death (by all causes) of up to $28 \%[3,4]$. There is also evidence $[5,6]$ that links the consumption of certain foods with the increased or decreased likelihood of suffering from certain diseases. All of these findings on the importance of diet have been taken into account by various organisations that have published dietary guidelines [7]. The level of compliance with these recommendations has in turn served as the basis for constructing indices that seek to assess the diet quality (DQ) of various groups and populations. Not only have these indices proven to be useful tools for assessing alimentary practices (e.g., diet diversity, moderation, 
etc.), but their use is also recommended for studies on the DQ of the general population as well as more targeted groups [8]. Internationally, these indices have been used to study the DQ of a range of groups [9-12], including university students [13,14]. Students, in particular, are an important target audience for public health actions, seeing that entering university constitutes a drastic change in lifestyle that can bring about new challenges and meaningfully affect the students' habits and health. Rivalry between classmates, the pressure to succeed academically, changes in workload and support networks, new types of relationships, and, in some instances, moving away from home are all factors that can trigger new, risky behaviours that may compromise the future health of university students $[15,16]$. These young adults find themselves in a crucial moment in terms of acquiring and reinforcing many habits that impact health. When it comes to dietary habits, university is the time when previously learned patterns can be cemented, or new patterns can be learned and replace old ones $[17,18]$. Many variables can exert influence on the ways that university students nourish themselves, including individual factors (e.g., the lack of self-discipline or time constraints), support networks (e.g., the influence of peers or the lack of parental monitoring), the local environment (e.g., accessibility or the appeal and price of certain food products) as well as the macro environment (e.g., advertising) $[19,20]$. Other sociodemographic variables have also been connected to the DQ of university students, including the following: living alone [21], gender [22], satisfaction with one's studies and academic performance [23], lack of information [24] as well as anxiety and depression [25].

In Spain, there have been numerous studies on the DQ of the general population $[7,26-28]$ and even clinical populations [29,30]. That said, more targeted work on the DQ of young people and university students in particular has been scarcer, and the studies that do exist have generally relied on small samples and somewhat indirect approximations of DQ based on the adherence to the Mediterranean diet. Accordingly, there is an important gap in the research that needs to be filled, especially given that universities can easily communicate with large groups of young adults and hence could become excellent agents for promoting healthier dietary practices. With this in mind, this study's objectives were twofold: first, to assess Spanish university students' DQ and adherence to the National Food-Based Dietary Guidelines (NFBDG) [31]; second, to identify possibly linked factors.

\section{Materials and Methods}

\subsection{Design and Study Population}

A descriptive cross-sectional study was carried out among a group of undergraduate students from the San Jorge University in Zaragoza (Aragon, Spain). Information about the research objectives was provided and students were recruited in the classroom during the second semester of the 2020-2021 academic year (specifically, in March and April of 2021). A total of 1309 students out of the 2219 enrolled at the university were asked to participate in the study by anonymously filling out a series of questionnaires. There were 151 students who declined to participate, while the responses of an additional 103 students were discarded due to gaps in the provided information (Figure 1).

\subsection{Data Collection}

Sociodemographic data (age, gender, place of residence, and marital status), anthropometric measurements (height and weight, which were used to calculate BMI), information about mental health history (signs of depression, anxiety, and stress), and lifestyle (current tobacco and alcohol intake, sleep, level of physical activity, time spent sitting, and diet) were collected. The BMI variable was categorised according to the classification of the World Health Organization (WHO) [32], namely as underweight $\left(<18.5 \mathrm{~kg} / \mathrm{m}^{2}\right)$, normal weight $\left(18.5-24.9 \mathrm{~kg} / \mathrm{m}^{2}\right)$, overweight $\left(25-29.9 \mathrm{~kg} / \mathrm{m}^{2}\right)$, and obese $\left(\geq 30 \mathrm{~kg} / \mathrm{m}^{2}\right)$. However, we combined the participants who were either overweight or obese into one group—overweight/obese $\left(\geq 25 \mathrm{~kg} / \mathrm{m}^{2}\right)$ —in order to increase the sample-size comparability of the groups. The sociodemographic, anthropometric, and smoking data were all self-reported using a questionnaire made specifically for collecting this information. 
San Jorge University undergraduates $(n=2219)$

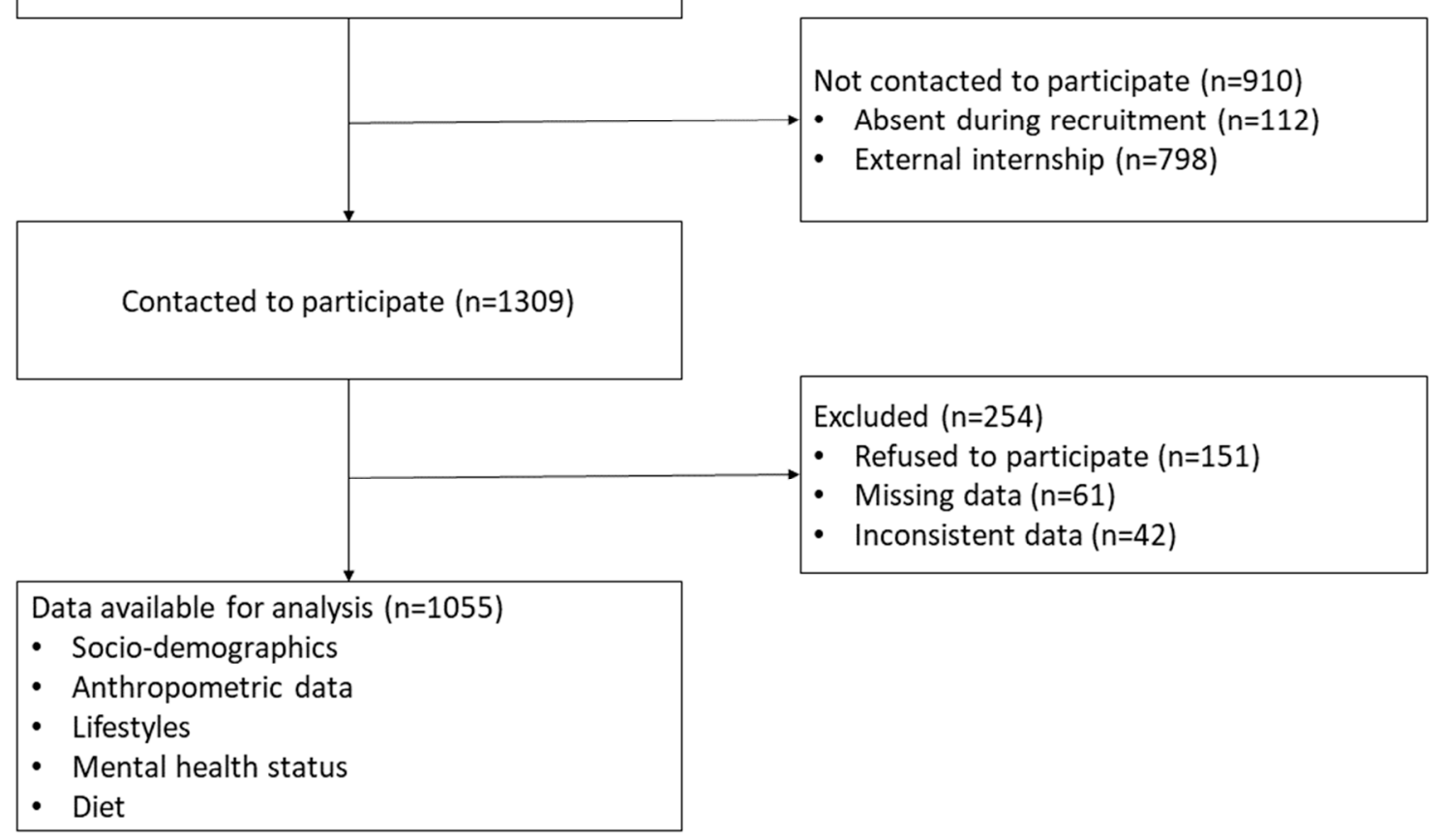

Figure 1. Study flow chart.

Data on the mental health of participating students were gathered through the Depression, Anxiety, Stress Scales-21 (DASS-21) [33]. This scale is an abridged version of the DASS-42 and was validated for the study of Spanish university students in 2010 [34]. DASS-21 consists of three sub-scales (depression, anxiety, and stress) with seven Likertstyle questions (with choices between 0 and 3 ) in each section. The total score of each sub-scale is multiplied by two so that results can be compared with those from the DASS-42. Next, the subjects were classified according to the following criteria:

- Anxiety: Normal (0-7 points), mild (8-9), moderate (10-14), severe (15-19), and extremely severe $(>19)$;

- Depression: Normal (0-9 points), mild (10-13), moderate (14-20), severe (21-27), and extremely severe $(>27)$;

- Stress: Normal (0-14 points), mild (15-18), moderate (19-25), severe (26-33), and extremely severe $(>33)$.

Data on alcohol intake were collected through the CAGE questionnaire, which has been validated for studying Spaniards by Rodríguez Martos et al. [35]. This questionnaire consists of four items with two possible responses (Yes or No). Consumption is deemed problematic when two or more questions are answered affirmatively.

Sleep quality was assessed using the Insomnia Severity Index (ISI) in its Spanish version [36]. This tool has previously been used to measure this construct in similar populations $[37,38]$. In its Spanish version, the ISI comprises 7 items measuring three different components of insomnia, namely (1) nature of insomnia, (2) severity of insomnia symptoms, and (3) impact of insomnia on daily function. Each item is rated on a 5-point Likert scale ranging from 0 to 4 points. The global score, ranging from 0 to 28 , is obtained by adding the scores from each individual item. The results are classified as follows: (1) no insomnia (0-7 points), (2) sub-threshold insomnia (8-14 points), (3) moderate insomnia (15-21 points), severe insomnia (22-28 points).

Physical activity and sedentary time were assessed using the short version of the International Physical Activity Questionnaire (IPAQ-SF). This research tool, which has been validated for the study of Spanish university students [39], measures the intensity, 
frequency, and duration of physical activity over the last seven days. IPAQ-SF determines a mean of daily sedentary time and allows researchers to obtain two types of data concerning physical activity: first, it offers a calculation of the metabolic equivalent of tasks (METs), taking the type of activity (walking, moderate physical activity, and vigorous physical activity) and the time spent on the activity into account; secondly, the tool allows researchers to classify individuals into three categories of physical activity (low, moderate, high) [40].

DQ was assessed using the Spanish Healthy Eating Index (SHEI) [26]. This tool comprises 10 items measured on a 5 -point Likert scale. Points for each answer $(0=$ no adherence, $2.5,5,7.5$, or $10=$ full adherence) are given based on the participant's degree of adherence to the NFBDG recommendations for the frequency of consumption of specific foods [31]. Specifically, the SHEI measures the frequency of consumption of bread and grains, vegetables, fruit, dairy products, meat (including eggs), legumes, cold meats and cuts, sweets, soft drinks with sugar, and diet variety. The diet variety variable is calculated a posteriori by the researcher based on the participant's report of daily and weekly food consumption (1 point is awarded for each weekly recommendation and 2 points for each daily recommendation that is fully met or adhered to). Supplementary Table S1 details the specific criteria for scoring each of these categories. The final score falls between 0 and 100 points, which is calculated by adding the scores from each category. Based on the results, diet can be classified as follows: healthy $(>80)$, needing change $(51-80)$, and inadequate $(<51)[26]$.

\subsection{Data Analysis}

The characteristics of the sample were summarised using mean and standard deviation for the continuous variables, and frequency and percentage for the nominal ones. The Kolmogorov-Smirnov test was used to check the normality of DQ (SHEI score). Next, a multiple linear regression analysis was carried out (enter method) to determine which factors were associated with DQ (SHEI score). The covariates included in the multiple linear regression model were age, gender, BMI (WHO categories), life arrangement, marital status, smoking status, alcohol consumption (CAGE categories), physical activity (IPAQ categories), sedentary time, sleep quality (ISI categories), and symptoms of depression, anxiety, and stress (DASS-21 categories).

The model's goodness-of-fit was assessed through $\mathrm{R}^{2}$. Furthermore, the diagnostic of collinearity of the final regression model showed tolerance levels over 0.6 for all included variables. The statistical analysis of the data was performed with the SPSS statistical package for Windows-Version 21 (IBM Corp, Armonk, NY, USA), accepting a significance level of $p<0.05$.

\section{Results}

The size of the study's final sample came to 1055 university students, with an average age of $21.74 \pm 5.15$. The majority of the participants were women (70.5\%), living with family $(66.4 \%)$, and non-smokers $(76.6 \%)$. Nearly a third reported high alcohol intake and nearly half reported a low level of physical activity. Furthermore, $33.9 \%$ of the students reported some degree of stress, $18.5 \%$ reported depression, $23.5 \%$ anxiety, and $43.1 \%$ insomnia. Other information about the sample is presented in Table 1.

The average SHEI score came up to $68.57 \pm 12.17$ (100 being the maximum). The vast majority of the participants reported an inadequate diet $(6.9 \%)$ or a diet needing changes $(75.6 \%)$, while only $17.4 \%$ had a healthy diet (Table 1$)$. The scores obtained by the participants ranged between $4.45 \pm 3.28$, for the consumption of sweets, and $9.27 \pm 2.82$, for the consumption of dairy products (Table 2).

Most participants showed a low level of compliance with the NFBDG recommendations concerning the frequency with which certain foods are consumed, especially for "bread and grains", "fruits", "meat", "vegetables"; in contrast, participants surpassed recommendations for the categories "cold meats and cuts" and "sweets" (Figure 2). Men and women reported similar dietary patterns; that said, the women more consistently 
followed the recommendations for the consumption of fruits and vegetables $(p<0.05)$, whereas the men more rigidly adhered to recommendations concerning meat $(p<0.05)$.

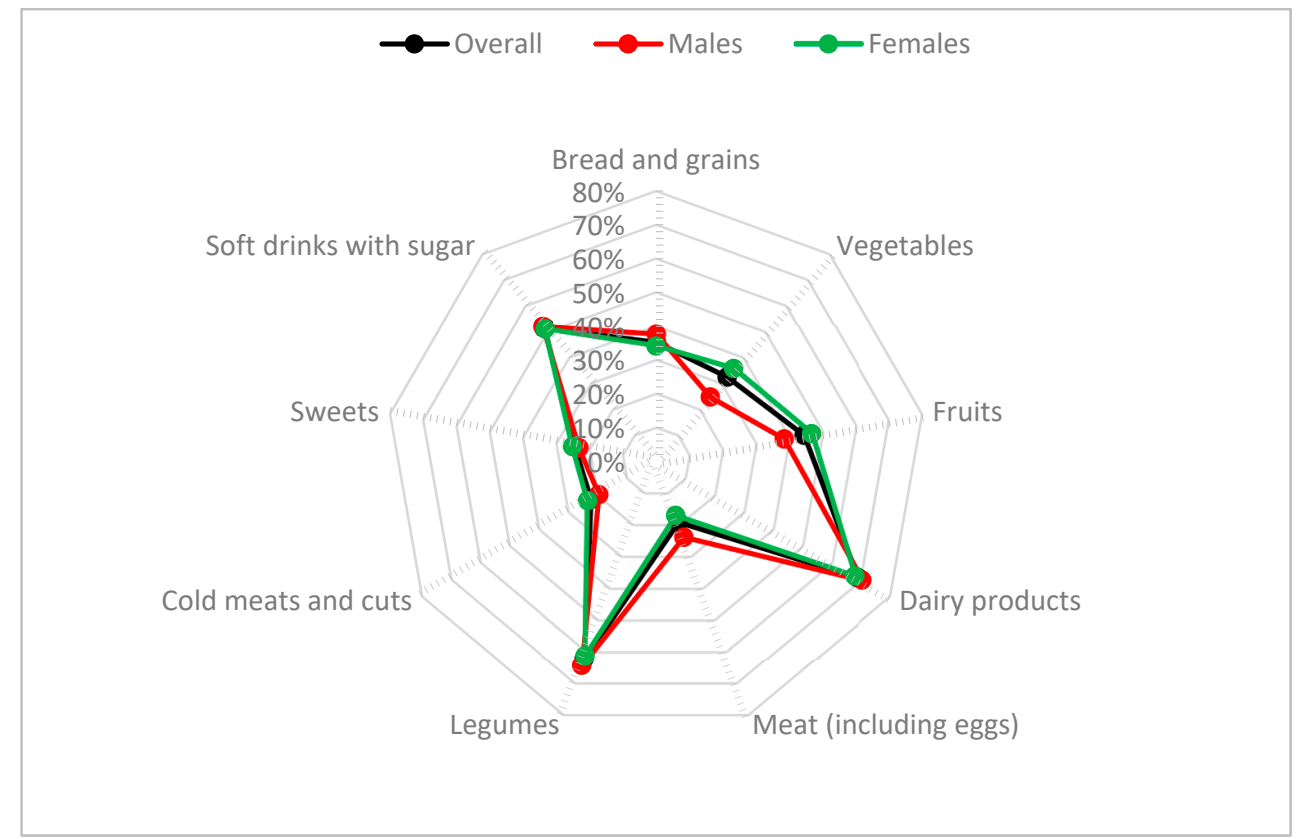

Figure 2. Percentage of students who adhere to the NFBDG-2016 [31] recommendations for the frequency with which certain foods should be consumed every week.

Table 1. Participant characteristics $(n=1055)$.

\begin{tabular}{|c|c|c|}
\hline Variable & & Mean $\pm \mathrm{SD} / n(\%)$ \\
\hline Age & & $21.74 \pm 5.15$ \\
\hline \multirow{2}{*}{ Gender } & Female & $744(70.5 \%)$ \\
\hline & Male & $311(29.5 \%)$ \\
\hline BMI $\left(\mathrm{kg} / \mathrm{m}^{2}\right)$ & & $22.15 \pm 3.48$ \\
\hline \multirow{3}{*}{ BMI Categories } & Underweight $\left(<18.5 \mathrm{~kg} / \mathrm{m}^{2}\right)$ & $160(15.2 \%)$ \\
\hline & Normal weight $\left(18.5-24.9 \mathrm{~kg} / \mathrm{m}^{2}\right)$ & $736(69.8 \%)$ \\
\hline & Overweight/obese $\left(\geq 25 \mathrm{~kg} / \mathrm{m}^{2}\right)$ & $159(15.1 \%)$ \\
\hline \multirow{3}{*}{ Living arrangement } & Living alone & $64(6.1 \%)$ \\
\hline & Living with a partner & $291(27.6 \%)$ \\
\hline & Living with family & $700(66.4 \%)$ \\
\hline \multirow{2}{*}{ Relationship status } & Currently in a relationship & $494(46.8 \%)$ \\
\hline & Currently not in a relationship & $561(53.2 \%)$ \\
\hline \multirow{2}{*}{ Smoking status (current) } & No & $535(76.6 \%)$ \\
\hline & Yes & $163(23.4 \%)$ \\
\hline CAGE score & & $0.48 \pm 0.78$ \\
\hline \multirow{2}{*}{ CAGE categories } & Problematic alcohol consumption & $343(32.5 \%)$ \\
\hline & Non-problematic alcohol consumption & $712(67.5 \%)$ \\
\hline SHEI score & & $68.57 \pm 12.17$ \\
\hline \multirow{3}{*}{ Diet quality } & Inadequate $(<51$ points $)$ & $73(6.9 \%)$ \\
\hline & Need changes (51-80 points) & $798(75.6 \%)$ \\
\hline & Healthy (>80 points) & $184(17.4 \%)$ \\
\hline
\end{tabular}


Table 1. Cont.

\begin{tabular}{|c|c|c|}
\hline Variable & & Mean $\pm \mathrm{SD} / n(\%)$ \\
\hline Physical activity (METs/week) & & $1877.03 \pm 1966.54$ \\
\hline \multirow{3}{*}{ Physical activity categories } & High & $236(22.4 \%)$ \\
\hline & Medium & $351(33.3 \%)$ \\
\hline & Low & $468(44.4 \%)$ \\
\hline Sedentary time (hours/day) & & $6.76 \pm 2.45$ \\
\hline \multirow{3}{*}{ Sedentary time categories } & $<3 \mathrm{~h} /$ day & $133(12.6 \%)$ \\
\hline & 3-6 h/day & $342(32.4 \%)$ \\
\hline & $\geq 6 \mathrm{~h} /$ day & $580(54.9 \%)$ \\
\hline DASS-E score & & $12.39 \pm 8.08$ \\
\hline \multirow{5}{*}{ DASS-E categories } & No stress & $697(66.1 \%)$ \\
\hline & Mild stress & $121(11.5 \%)$ \\
\hline & Moderate stress & $174(16.5 \%)$ \\
\hline & Severe stress & $46(4.4 \%)$ \\
\hline & Extremely severe stress & $17(1.6 \%)$ \\
\hline DASS-D score & & $5.45 \pm 7.12$ \\
\hline \multirow{5}{*}{ DASS-D categories } & No depression & $859(81.4 \%)$ \\
\hline & Mild depression & $80(7.6 \%)$ \\
\hline & Moderate depression & $48(4.5 \%)$ \\
\hline & Severe depression & $38(3.6 \%)$ \\
\hline & Extremely severe depression & $30(2.8 \%)$ \\
\hline DASS-A score & & $4.84 \pm 5.75$ \\
\hline \multirow{5}{*}{ DASS-A categories } & No anxiety & $807(76.5 \%)$ \\
\hline & Mild anxiety & $83(7.9 \%)$ \\
\hline & Moderate anxiety & $95(9.0 \%)$ \\
\hline & Severe anxiety & $9(0.9 \%)$ \\
\hline & Extremely severe anxiety & $61(5.8 \%)$ \\
\hline ISI score & & $7.91 \pm 4.88$ \\
\hline \multirow{4}{*}{ Sleep quality } & No insomnia & $600(56.9 \%)$ \\
\hline & Sub-threshold insomnia & $333(31.6 \%)$ \\
\hline & Moderate insomnia & $114(10.8 \%)$ \\
\hline & Severe insomnia & $8(0.8 \%)$ \\
\hline
\end{tabular}

Table 2. SHEI scores of the participants $(n=1055)$.

\begin{tabular}{|c|c|c|c|c|}
\hline Food Group & Mean \pm SD & Min. & Max. & Mode \\
\hline Bread and grains & $7.27 \pm 3.25$ & 0 & 10 & 10 (Consumed daily) \\
\hline Vegetables & $8.38 \pm 2.91$ & 0 & 10 & 10 (Consumed daily) \\
\hline Fruits & $8.23 \pm 3.54$ & 0 & 10 & 10 (Consumed daily) \\
\hline Dairy products & $9.27 \pm 2.82$ & 0 & 10 & 10 (Consumed daily) \\
\hline Meat & $6.90 \pm 2.83$ & 0 & 10 & 7.5 ( 3 or more times a week but not daily) \\
\hline Legumes & $9.17 \pm 1.97$ & 0 & 10 & 7.5 ( 3 or more times a week but not daily) \\
\hline Cold meats and cuts & $6.29 \pm 3.75$ & 0 & 10 & 5 (Once or twice a week) \\
\hline Sweets & $4.45 \pm 3.28$ & 0 & 10 & 5 (Once or twice a week) \\
\hline Soft drinks with sugar & $8.62 \pm 3.36$ & 0 & 10 & 7.5 (Less than once a week) \\
\hline SHEI score & $68.57 \pm 12.17$ & 25 & 96.5 & 70.5 (Need changes) \\
\hline
\end{tabular}


Through the multiple linear regression analysis, we found that being older, being female, not having a stable partner as well as having a low or high body weight independently correlated with a better DQ $(p<0.05)$. On the other hand, demonstrating signs of depression, anxiety, stress or insomnia, living alone, smoking, having an unactive lifestyle, being sedentary, and a high alcohol intake were all linked independently with lower SHEI scores $(p<0.05)$. This model's predictive power for DQ was determined to be $37.7 \%\left(\mathrm{R}^{2}=0.38\right)($ Table 3$)$.

Table 3. Factors related to diet quality. Multiple linear regression model *.

\begin{tabular}{|c|c|c|c|c|}
\hline Independent Variable & B (CI 95\%) & Std. Error & $\beta$ & $p$ \\
\hline \multicolumn{5}{|l|}{ Age. <20 years (Ref.) } \\
\hline $20-24.9$ & $3.54(2.05,5.04)$ & 0.76 & 0.14 & 0.00 \\
\hline$\geq 25$ & $4.76(2.68,6.85)$ & 1.06 & 0.14 & 0.00 \\
\hline \multicolumn{5}{|l|}{ Gender. Male (Ref.) } \\
\hline Female & $2.47(0.94,4.00)$ & 0.781 & 0.09 & 0.00 \\
\hline \multicolumn{5}{|l|}{ BMI categories. Normal weight (Ref.) } \\
\hline Underweight $\left(<18.5 \mathrm{~kg} / \mathrm{m}^{2}\right)$ & $3.55(1.63,5.48)$ & 0.98 & 0.10 & 0.00 \\
\hline Overweight/obese $\left(\geq 25 \mathrm{~kg} / \mathrm{m}^{2}\right)$ & $6.42(4.53,8.31)$ & 0.96 & 0.19 & 0.00 \\
\hline \multicolumn{5}{|c|}{ Living arrangement. Living with family (Ref.) } \\
\hline Living alone & $-11.49(-14.27,-8.71)$ & 1.42 & -0.22 & 0.00 \\
\hline Living with a partner & $-0.50(-2.06,1.07)$ & 0.80 & -0.02 & 0.53 \\
\hline \multicolumn{5}{|c|}{ Relationship status. Currently in a relationship (Ref.) } \\
\hline Currently not in a relationship & $3.63(2.01,5.25)$ & 0.83 & 0.15 & 0.00 \\
\hline \multicolumn{5}{|l|}{ Smoking status. Not a smoker (Ref.) } \\
\hline Smoker & $-2.82(-4.41,-1.24)$ & 0.81 & -0.10 & 0.00 \\
\hline \multicolumn{5}{|c|}{ CAGE Categories. Non-problematic alcohol consumption (Ref.) } \\
\hline Problematic alcohol consumption & $-1.82(-3.20,-0.45)$ & 0.702 & -0.070 & 0.01 \\
\hline \multicolumn{5}{|l|}{ Physical activity. Medium (Ref.) } \\
\hline High PA & $1.74(-0.05,3.53)$ & 0.91 & 0.06 & 0.06 \\
\hline Low PA & $-2.77(-4.45,-1.09)$ & 0.86 & -0.11 & 0.00 \\
\hline \multicolumn{5}{|l|}{ Sedentary time. $3-6 \mathrm{~h}$ per day } \\
\hline$<3 \mathrm{~h} /$ day & $-0.29(-2.48,1.90)$ & 1.11 & -0.01 & 0.80 \\
\hline$\geq 6$ h/day & $-2.40(-3.86,-0.93)$ & 0.75 & -0.10 & 0.00 \\
\hline \multicolumn{5}{|l|}{ DASS-E categories. No stress (Ref.) } \\
\hline Mild stress & $12.10(9.63,14.57)$ & 1.26 & 0.32 & 0.00 \\
\hline Moderate stress & $-1.08(-3.08,0.92)$ & 1.02 & -0.03 & 0.29 \\
\hline Severe stress & $-0.29(-3.93,3.35)$ & 1.85 & -0.00 & 0.88 \\
\hline Extremely severe stress & $-5.56(-11.37,0.24)$ & 2.96 & -0.06 & 0.06 \\
\hline \multicolumn{5}{|c|}{ DASS-D categories. No depression (Ref.) } \\
\hline Mild depression & $2.13(-1.00,5.27)$ & 1.60 & 0.05 & 0.18 \\
\hline Moderate depression & $-3.23(-6.71,0.25)$ & 1.77 & -0.05 & 0.07 \\
\hline Severe depression & $-18.04(-22.12,-3.97)$ & 2.07 & -0.28 & 0.00 \\
\hline Extremely severe depression & $-7.77(-12.22,-3.33)$ & 2.26 & -0.11 & 0.00 \\
\hline \multicolumn{5}{|l|}{ DASS-A categories. No anxiety (Ref.) } \\
\hline Mild anxiety & $-3.25(-5.91,-0.60)$ & 1.35 & -0.07 & 0.01 \\
\hline Moderate anxiety & $-3.32(-5.93,-0.70)$ & 1.33 & -0.08 & 0.01 \\
\hline Severe anxiety & $-10.96(-18.25,-3.66)$ & 3.72 & -0.08 & 0.00 \\
\hline Extremely severe anxiety & $-1.29(-5.18,2.61)$ & 1.98 & -0.02 & 0.52 \\
\hline \multicolumn{5}{|l|}{ ISI categories. No insomnia (Ref.) } \\
\hline Sub-threshold insomnia & $-4.93(-6.50,-3.37)$ & 0.79 & -0.19 & 0.00 \\
\hline Moderate insomnia & $-6.62(-9.11,-4.14)$ & 1.27 & -0.17 & 0.00 \\
\hline Severe insomnia & $-13.51(-21.46,-5.56)$ & 4.05 & -0.10 & 0.00 \\
\hline
\end{tabular}




\section{Discussion}

Based on the recommendations of the National Food-Based Dietary Guidelines [31], our findings suggest that university students' diet quality is generally poor. Our participants consumed insufficient amounts of "fruit" and "vegetables" and excessive amounts of "cold meats and cuts" and "sweets". Factors that predicted a diet of worse quality were being male, living alone, maintaining low levels of physical activity, smoking, consuming alcohol, leading a sedentary lifestyle, experiencing psychological distress, and insomnia. In contrast, participants with low or high body weights showed signs of a higher quality diet.

Only $17.4 \%$ of the participants reported having a healthy diet. The present results are similar to those previously obtained by using SHEI to study Spanish university students [22,41-43]. They are, however, distinctly lower than the results from studies of the general Spanish population, for which between $28 \%$ and $35.8 \%$ of the participants reported having a healthy diet $[26,27,29]$. These results could be explained in two ways that are not mutually exclusive. First, the newly found liberty and independence associated with university life could allow students to let themselves go and overindulge in low-quality foods and alcohol. This does not necessarily mean that these individuals will not improve their DQ in the future after finishing their studies; indeed, they very well could do so. In this vein, previous studies carried out in England, Spain, and Lebanon have shown that some students opt for a poorer diet and gain a significant amount of weight in the first year of university, a phenomenon popularly referred to as "the Freshman $15^{\prime \prime}$ [44-46]. The second argument is that these trends reflect a more general tendency and could therefore imply that the DQ of Spaniards could decline in the future. The fact that age was positively associated with DQ in our sample lends support to this hypothesis. Indeed, research has shown that there has continually been less adherence to the Mediterranean diet in Spain $[47,48]$, a diet that has been shown to be healthy and traditional in the country. This, however, does not appear to be a trend that is only valid in Spain, since researchers throughout Europe have detected a decrease in DQ over the last decade [49].

Internationally, researchers have found a remarkable range in the percentage of university students who have a healthy diet, ranging between $1.8 \%$ and $57 \%$ [18,50-53]. These differences, for the most part, can be explained in terms of the different socioeconomic realities and living arrangements of the various countries studied. For example, whereas $57 \%$ of Thai students reported following an inadequate diet [50], only $2.03 \%$ of Northern European students followed an unhealthy diet [18].

What deserves special attention is how student habits do not conform to the national alimentary guidelines for the majority of food groups. In fact, over $50 \%$ of the participants complied with recommendations in only three of the 10 variables included in the SHEI (dairy products, legumes, and soft drinks with sugar). Likewise, the results show a low level of fruit and vegetable consumption $(44.3 \%$ and $32.5 \%$ of recommended frequency, respectively). Prima facie, these results may come as a surprise since Spain has a reputation for the quality of its agricultural products. However, similar trends have already been observed in Spanish university students $[54,55]$ and the general population $[7,56]$ that support the present findings.

In line with previous studies carried out in Tunisia and Canada [52,57], being a woman is associated with a better DQ. The relationship between gender and diet are conditioned by a suite of physiological, psychological, and sociocultural factors. Thus, women generally believe in the importance of a healthy diet, are more likely to monitor their body weight, and frequently express greater concern over their own eating habits [58-60].

The connection between DQ and BMI is controversial. From a biological point of view, it is plausible that a low-quality diet could be associated with deviations (whether higher or lower) from what experts recommend as a healthy body weight. As a corollary, a high-quality diet would be expected to favour healthy body weight. However, various studies have demonstrated how this is not always the case [61,62]. Our analysis found a Ushaped relation between the profiles of BMI and DQ (healthy body weight $<$ low and high weights). These results should be viewed with caution given this study's qualitative means 
of assessing DQ. However, it is possible that in a developed country such as Spain, young university students who are over or underweight may be more informed and conscious about what constitutes a healthy and balanced diet; perhaps some are influenced by the enduring canon of beauty in the West (based on being thin), while others seek to have a healthier weight.

The participants that lived alone showed a poorer DQ than those who lived with family members or flat mates. This same phenomenon has been repeatedly found in other studies involving samples of European students $[21,63]$. There are various reasons that explain why students who live alone were less likely to adopt a healthy diet; these include, but are not limited to, the following: changing lifestyle, the comfort and convenience of fast food, taste, students' physical and social environment, and awareness of weight [64].

The fact that being in a stable relationship was associated with a poorer DQ in our sample appears to support the prevalent idea that when we enter a serious relationship, we often do not take as good care of ourselves as before. Available research on the issue has shown that people who are overweight or obese (especially women) have more difficulty finding a partner than those who are not overweight [65]. Developing this idea, van Woerden et al. [66] suggest that there is a selection bias related to weight for beginning (but not ending) romantic relationships. In their study, these authors observed that for students that were single at moment $\mathrm{A}$, the increase of each BMI unit reduced their chances of finding a partner at moment B (four months later) by $9 \%$. Taking these results into account, one could infer that an individual seeking to start a new relationship might be more inclined to regulate his/her diet than someone uninterested in finding a new partner.

Among the study population, a clear association was observed between DQ and both unhealthy lifestyle choices (i.e., low levels of physical activity, a highly sedentary lifestyle, high alcohol intake, or smoking) as well as psychological health (i.e., the presence of stress, anxiety, depression, or insomnia). Previous studies have shown the tendency for unhealthy lifestyle choices (including low-quality diet) to cluster among Spanish university students [67-70]. The same holds for the relation between mental health and DQ [22,23,41]. Unhealthy habits (e.g., high alcohol intake, smoking, or certain dietary behaviours) have often been detected among those suffering from psychological distress and have been identified as passive coping mechanisms based on avoidance and/or escape [71]. However, one should not dismiss a bidirectional relationship between mental health and certain unhealthy lifestyle choices such as poor DQ. In fact, several recent studies have reported a strong correlation between a healthy diet and psychological wellbeing. Therefore, healthy diets such as the Mediterranean, which is rich in fresh fruits and vegetables, could be associated with higher levels of happiness and mental health [72-74], whereas certain gaps in the diet could be associated with a deterioration in mental health [71,75]. A similar connection can be observed when it comes to sleep quality; participants suffering from insomnia also reported a worse DQ. These results are consistent with findings in the broader scholarly literature on the topic. Numerous experimental studies have shown how partial sleep deprivation leads to an increased intake of fats [76,77], snacks [78,79], foods rich in rapidly absorbed carbohydrates [80,81], and inconsistent or shifting mealtimes [76]. Similarly, observational studies have provided further evidence of poorer DQ among people who have a lower quality of sleep in Iran and the USA [82,83]. Different explanations have been proffered to illuminate the phenomenon. More waking hours means more time for eating, changes in the level of hormones that regulate appetite (leptin and ghrelin), increased processing of hedonic stimuli in the brain (providing a greater reward from food), and shifting eating schedules [84]. However, it may not only be lack of sleep that affects diet; certain foods and nutrients can themselves influence sleep quality. For example, high-carb diets and foods that contain tryptophan, melatonin, and phytonutrients (e.g., cherries) seem to be linked with higher sleep quality [85].

As far as the authors are aware, this is the first study that analyses DQ and a large number of sociodemographic and behavioural variables among a large sample of Spanish university students. We believe that the obtained results can be generalised to the 
larger body of Spanish university students, not only due to the large sample size but also because of the standardised procedures used to collect data as well as the plausibility of the associations detected in the data analysis. Accordingly, this would allow us to trace a reliable picture of university students' DQ as well as its associated factors. Such information is crucial since it can assist in the development and implementation of both diagnostic tools as well as educational activities concerning a healthy diet. That said, the study also has several limitations that need to be underscored. First, the transversal design makes it possible to detect associations, but it does not allow us to determine a cause-and-effect relationship or direction of influence. Second, the type of sampling used, a choice based on convenience and available resources, does impinge on our ability to draw generalisations from these results even though, we should note, the profile of our sample (i.e., predominantly female) does match the broader demographics of university students in Aragon. Third, data was self-reported by the participants, which means that one cannot rule out the possibility of faulty memory or the playing down of certain information such as body weight $[86,87]$. Fourth, our data was collected when the COVID-19 pandemic and the resulting public health measures were well underway in Spain. This fact provides valuable information about Spanish university students' diet in the current context, and, in all likelihood, our results reflect the pandemic's impact on the lives and dietary habits of university students. However, the data does not allow us to determine the precise ways that the current situation has affected students' diets. Nevertheless, it is worth mentioning that other researchers have observed a decline in DQ since the beginning of the pandemic; lockdown measures have, on the one hand, led to a decline in the consumption of fruits and vegetables [88], and on the other hand, to an increase in the consumption of unhealthy foods (e.g., highly-processed foods, snacks, and frozen foods) [89-91]. Furthermore, the SHEI questionnaire only takes into account the frequency with which foods are consumed and not the quantity that is ingested. For this reason, it cannot offer information concerning the intake of nutrients or calories. Despite these limitations, there were three main reasons that we chose this tool: it is a questionnaire specifically adapted to Spanish alimentary habits; it has repeatedly been shown to be well-equipped to assess the DQ of Spaniards [27,92,93]; finally, the original questionnaire from which it was derived has been validated with plasma biomarkers in previous studies [94,95]. Given the limitations listed above, further research on the present issue is needed, including a longitudinal study as well as a quantitative approach to evaluating the diet of Spanish university students.

\section{Conclusions and Recommendations}

The present findings reveal that a large portion of university students have a poor DQ and do not closely adhere to alimentary recommendations. Therefore, it is necessary to encourage changes in current dietary patterns. Factors such as living arrangement, certain unhealthy habits (high alcohol intake, a sedentary lifestyle, smoking, and the presence of psychological distress and insomnia) predict DQ and can therefore be used to help tailor and direct action. It is indeed essential that educational institutions and health services undertake future action to promote better DQ among university students. We recommend a global approach to the issue that takes into account the factors related to poor DQ. Any such actions ought to take into consideration the following recommendations:

(1) the early detection of trends of poor DQ among students entering university as part of existing systems that offer students support;

(2) activities that aim to interrupt and prevent unhealthy dietary habits such as providing gender-specific information about immediate health concerns or organising community-wide public health campaigns that ensure that students have access to needed resources and affordable healthy foods;

(3) the empowerment of students by encouraging, for example, the acquisition of skills for making dietary choices and increasing resilience so that they can develop their own adaptive strategies to confront dietary problems and avoid unhealthy dietary habits; 
(4) the consideration and handling of any underlying mental health conditions that could be present among university students with poor DQ.

Supplementary Materials: The following are available online at https:/ /www.mdpi.com/article/10 .3390/nu13103512/s1, Table S1: Criteria for scoring the Spanish Healthy Eating Index (SHEI).

Author Contributions: Conceptualization, E.R.-A. and B.A.J.; methodology, E.R.-A., I.A.-S., and B.A.J.; formal analysis, E.R.-A., J.-M.G.-L., and E.E.-S.; investigation, E.R.-A., B.A.J., I.A.-S., J.-M.G.-L., E.E.-S., and B.M.-A.; writing—original draft preparation, E.R.-A.; writing—review and editing, B.A.J., I.A.-S., J.-M.G.-L., E.E.-S., and B.M.-A.; supervision, B.A.J. and J.-M.G.-L. All authors have read and agreed to the published version of the manuscript.

Funding: This research received no external funding.

Institutional Review Board Statement: The study was conducted according to the guidelines of the Declaration of Helsinki, and approved by the Research Ethics Committee of the Autonomous Community of Aragón (CEICA) (protocol code C.I. PI09/062X and date of approval 07/08/2017).

Informed Consent Statement: Informed consent was obtained from all subjects involved in the study.

Data Availability Statement: The data presented in this study are available on request from the corresponding author. The data are not publicly available as they contain information that could compromise the privacy of research participants.

Conflicts of Interest: The authors declare no conflict of interest.

\section{References}

1. Jankovic, N.; Geelen, A.; Streppel, M.T.; de Groot, L.C.; Kiefte-de Jong, J.C.; Orfanos, P.; Bamia, C.; Trichopoulou, A.; Boffetta, P.; Es Bobak, M.; et al. WHO Guidelines for a Healthy Diet and Mortality from Cardiovascular Disease in European and American Elderly: The CHANCES Project. Am. J. Clin. Nutr. 2015, 102, 745-756. [CrossRef]

2. Jankovic, N.; Geelen, A.; Streppel, M.T.; de Groot, L.C.P.G.M.; Orfanos, P.; van den Hooven, E.H.; Pikhart, H.; Boffetta, P.; Trichopoulou, A.; Bobak, M.; et al. Adherence to a Healthy Diet According to the World Health Organization Guidelines and All-Cause Mortality in Elderly Adults from Europe and the United States. Am. J. Epidemiol. 2014, 180, 978-988. [CrossRef] [PubMed]

3. Liese, A.D.; Krebs-Smith, S.M.; Subar, A.F.; George, S.M.; Harmon, B.E.; Neuhouser, M.L.; Boushey, C.J.; Schap, T.E.; Reedy, J. The Dietary Patterns Methods Project: Synthesis of Findings across Cohorts and Relevance to Dietary Guidance. J. Nutr. 2015, 145, 393-402. [CrossRef] [PubMed]

4. Neelakantan, N.; Koh, W.-P.; Yuan, J.-M.; van Dam, R.M. Diet-Quality Indexes Are Associated with a Lower Risk of Cardiovascular, Respiratory, and All-Cause Mortality among Chinese Adults. J. Nutr. 2018, 148, 1323-1332. [CrossRef] [PubMed]

5. Micha, R.; Peñalvo, J.L.; Cudhea, F.; Imamura, F.; Rehm, C.D.; Mozaffarian, D. Association Between Dietary Factors and Mortality from Heart Disease, Stroke, and Type 2 Diabetes in the United States. JAMA 2017, 317, 912-924. [CrossRef]

6. Harrison, S.; Couture, P.; Lamarche, B. Diet Quality, Saturated Fat and Metabolic Syndrome. Nutrients 2020, 12, 3232. [CrossRef]

7. Martínez Valero, A.P.; Amo-Saus, E.; Pardo-García, I.; Escribano-Sotos, F. Calidad de la dieta en mayores de 65 años y factores socioeconómicos relacionados. Atención Primaria 2021, 53, 27-35. [CrossRef]

8. Gil, Á. Indicadores de Evaluación de La Calidad de La Dieta. Nutr. Hosp. 2015, 128-144. [CrossRef]

9. Asadi, Z.; Ghaffarian Zirak, R.; Yaghooti Khorasani, M.; Saedi, M.; Parizadeh, S.M.; Jafarzadeh-Esfehani, R.; Khorramruz, F.; Jandari, S.; Mohammadi-Bajgiran, M.; Zare-Feyzabadi, R.; et al. Dietary Inflammatory Index Is Associated with Healthy Eating Index, Alternative Healthy Eating Index, and Dietary Patterns among Iranian Adults. J. Clin. Lab. Anal. 2020, 34 , e23523. [CrossRef]

10. Murakami, K.; Livingstone, M.B.E.; Fujiwara, A.; Sasaki, S. Application of the Healthy Eating Index-2015 and the NutrientRich Food Index 9.3 for Assessing Overall Diet Quality in the Japanese Context: Different Nutritional Concerns from the US. PLOS ONE 2020, 15, e0228318. [CrossRef]

11. Sedaghat, F.; Heidari, Z.; Jalali, S.; Doustmohammadian, A.; Ehteshami, M.; Rashidkhani, B. Healthy Eating Index 2010 and Breast Cancer Risk. Nutr. Cancer 2018, 70, 860-866. [CrossRef] [PubMed]

12. Al-Ibrahim, A.A.; Jackson, R.T. Healthy Eating Index versus Alternate Healthy Index in Relation to Diabetes Status and Health Markers in U.S. Adults: NHANES 2007-2010. Nutr. J. 2019, 18, 26. [CrossRef]

13. Tay, M.E.; Foster, E.; Stevenson, L.; Brownlee, I. The Adherence of Singaporean Students in Different Educational Institutions to National Food-Based Dietary Guidelines. Nutrients 2020, 12, 2995. [CrossRef]

14. Merhout, F.; Doyle, J. Socioeconomic Status and Diet Quality in College Students. J. Nutr. Educ. Behav. 2019, 51, 1107-1112. [CrossRef] 
15. El Ansari, W.; Stock, C. Is the Health and Wellbeing of University Students Associated with Their Academic Performance? Cross Sectional Findings from the United Kingdom. Int. J. Environ. Res. Public Health 2010, 7, 509-527. [CrossRef]

16. Deliens, T.; Clarys, P.; De Bourdeaudhuij, I.; Deforche, B. Determinants of Eating Behaviour in University Students: A Qualitative Study Using Focus Group Discussions. BMC Public Health 2014, 14, 53. [CrossRef] [PubMed]

17. Sogari, G.; Velez-Argumedo, C.; Gómez, M.I.; Mora, C. College Students and Eating Habits: A Study Using an Ecological Model for Healthy Behavior. Nutrients 2018, 10, 1823. [CrossRef] [PubMed]

18. Suliga, E.; Cieśla, E.; Michel, S.; Kaducakova, H.; Martin, T.; Śliwiński, G.; Braun, A.; Izova, M.; Lehotska, M.; Kozieł, D.; et al. Diet Quality Compared to the Nutritional Knowledge of Polish, German, and Slovakian University Students-Preliminary Research. Int. J. Environ. Res. Public Health 2020, 17, 9062. [CrossRef]

19. Kabir, A.; Miah, S.; Islam, A. Factors Influencing Eating Behavior and Dietary Intake among Resident Students in a Public University in Bangladesh: A Qualitative Study. PLoS ONE 2018, 13, e0198801. [CrossRef]

20. Vélez-Toral, M.; Rodríguez-Reinado, C.; Ramallo-Espinosa, A.; Andrés-Villas, M. "It's Important but, on What Level?": Healthy Cooking Meanings and Barriers to Healthy Eating among University Students. Nutrients 2020, 12, 2309. [CrossRef] [PubMed]

21. Bárbara, R.; Ferreira-Pêgo, C. Changes in Eating Habits among Displaced and Non-Displaced University Students. Int. J. Environ. Res. Public Health 2020, 17, 5369. [CrossRef]

22. Ramón-Arbués, E.; Martínez Abadía, B.; Granada López, J.M.; Echániz Serrano, E.; Pellicer García, B.; Juárez Vela, R.; Guerrero Portillo, S.; Saéz Guinoa, M. Eating behavior and relationships with stress, anxiety, depression and insomnia in university students. Nutr. Hosp. 2019, 36, 1339-1345. [CrossRef] [PubMed]

23. Whatnall, M.C.; Patterson, A.J.; Siew, Y.Y.; Kay-Lambkin, F.; Hutchesson, M.J. Are Psychological Distress and Resilience Associated with Dietary Intake Among Australian University Students? Int. J. Environ. Res. Public Health 2019, 16, 4099. [CrossRef] [PubMed]

24. El Hajj, J.S.; Julien, S.G. Factors Associated with Adherence to the Mediterranean Diet and Dietary Habits among University Students in Lebanon. J. Nutr. Metab. 2021, 2021, 6688462. [CrossRef] [PubMed]

25. Wattick, R.A.; Hagedorn, R.L.; Olfert, M.D. Relationship between Diet and Mental Health in a Young Adult Appalachian College Population. Nutrients 2018, 10, 957. [CrossRef] [PubMed]

26. Norte Navarro, A.I.; Ortiz Moncada, R. Spanish diet quality according to the healthy eating index. Nutr. Hosp. 2011, 26, 330-336. [CrossRef] [PubMed]

27. Hernández Galiot, A.; Goñi Cambrodón, I. Calidad de La Dieta de La Población Española Mayor de 80 Años No Institucionalizada. Nutr. Hosp. 2015, 31, 2571-2577. [CrossRef]

28. Valdés, J.; Grau, M.; Subirana, I.; Marrugat, J.; Covas, M.-I.; Schröder, H. Secular Trends in Energy Intake and Diet Quality in a Mediterranean Population. Ann. Nutr. Metab. 2009, 54, 177-183. [CrossRef] [PubMed]

29. Cebrino, J.; Portero de la Cruz, S. Diet Quality According to Mental Status and Associated Factors during Adulthood in Spain. Nutrients 2021, 13, 1727. [CrossRef]

30. Varoucha-Azcarate, A.C. Analysis of the Diet in a Spanish Prison and the Level of Perception in a Sample of Prisoners. Rev. Esp. Sanid. Penit. 2019, 21, 18-27. [CrossRef]

31. Bartrina, J.A.; Grupo Colaborativo de la Sociedad Española de Nutrición Comunitaria (SENC); Arija Val, A.; Maíz Aldalur, E.; de la Victoria Muñoz, E.; Ortega Anta, R.M.; Pérez-Rodrigo, C.; Quiles Izquierdo, J.; Rodríguez Martín, A.; Román Viñas, B.; et al. Dietary guidelines for the Spanish population (SENC, December 2016): The new graphic icon of healthy nutrition. Nutr. Hosp. 2016, 33, 1-48. [CrossRef]

32. World Health Organization. Body Mass Index-BMI. Available online: https://www.euro.who.int/en/health-topics/diseaseprevention/nutrition/a-healthy-lifestyle/body-mass-index-bmi (accessed on 11 June 2021).

33. Lovibond, P.F.; Lovibond, S.H. The Structure of Negative Emotional States: Comparison of the Depression Anxiety Stress Scales (DASS) with the Beck Depression and Anxiety Inventories. Behav. Res. Ther. 1995, 33, 335-343. [CrossRef]

34. Pedrero, E.F.; Piñeiro, M.; de las, M.P.; Giráldez, S.L.; Fernández, J.M. Propiedades psicométricas de la Depresión Anxiety and Stress Scales-21 (DASS-21) en universitarios españoles. Ansiedad Estrés 2010, 16, 215-226.

35. Rodríguez Martos, A.; Navarro, R.; Vecino, C.; Pérez, R. Validación de Los Cuestionarios KFA (CBA) y CAGE Para El Diagnóstico Del Alcoholismo. Droga-Alcohol 1986, 11, 132-139.

36. Sierra-Guerra, K.L.; Viveros-Contreras, C.; Martínez-Carrillo, G.; Hernández-León, O.; Caballero-Ambriz, G. Calidad de Vida En Pacientes Con Cáncer de Próstata, Operados de Prostatectomía Radical Laparoscópica. Rev. Mex. Urol. 2014, 74, 133-140. [CrossRef]

37. Dietch, J.R.; Taylor, D.J.; Sethi, K.; Kelly, K.; Bramoweth, A.D.; Roane, B.M. Psychometric Evaluation of the PSQI in U.S. College Students. J. Clin. Sleep Med. 2016, 12, 1121-1129. [CrossRef]

38. Veqar, Z.; Hussain, M.E. Validity and Reliability of Insomnia Severity Index and Its Correlation with Pittsburgh Sleep Quality Index in Poor Sleepers among Indian University Students. Int. J. Adolesc. Med. Health 2017, 32, 20160090. [CrossRef]

39. Rodríguez-Muñoz, S.; Corella, C.; Abarca-Sos, A.; Zaragoza, J. Validation of Three Short Physical Activity Questionnaires with Accelerometers among University Students in Spain. J. Sports Med. Phys. Fit. 2017, 57, 1660-1668. [CrossRef]

40. IPAQ. Scoring, Protocol-International Physical Activity Questionnaire. Available online: https://sites.google.com/site/theipaq/ scoring-protocol (accessed on 24 July 2021). 
41. Ramón-Arbués, E.; Gea-Caballero, V.; Granada-López, J.M.; Juárez-Vela, R.; Pellicer-García, B.; Antón-Solanas, I. The Prevalence of Depression, Anxiety and Stress and Their Associated Factors in College Students. Int. J. Environ. Res. Public Health 2020, 17, 7001. [CrossRef]

42. Amaral Alves, D.; Hernández Regidor, N.; Basabe Baraño, N.; Rocandio Pablo, A.M.; Arroyo Izaga, M. Body satisfaction and diet quality in female university students from the Basque Country. Endocrinol. Nutr. 2012, 59, 239-245. [CrossRef]

43. Telleria-Aramburu, N.; Bermúdez-Marín, N.; Rocandio, A.M.; Telletxea, S.; Basabe, N.; Rebato, E.; Arroyo-Izaga, M. Nutritional Quality and Carbon Footprint of University Students' Diets: Results from the EHU12/24 Study. Public Health Nutr. 2021, 1-13. [CrossRef] [PubMed]

44. Vadeboncoeur, C.; Foster, C.; Townsend, N. Freshman 15 in England: A Longitudinal Evaluation of First Year University Student's Weight Change. BMC Obes. 2016, 3, 45. [CrossRef]

45. Haidar, S.A.; de Vries, N.K.; Papandreou, D.; Rizk, R.; Karavetian, M. The Freshman Weight Gain Phenomenon: Does It Apply To. Open Access Maced. J. Med. Sci. 2018, 6, 2214-2220. [CrossRef]

46. Mihalopoulos, N.L.; Auinger, P.; Klein, J.D. The Freshman 15: Is It Real? J. Am. Coll. Health 2008, 56, 531-533. [CrossRef] [PubMed]

47. Bach-Faig, A.; Fuentes-Bol, C.; Ramos, D.; Carrasco, J.L.; Roman, B.; Bertomeu, I.F.; Cristià, E.; Geleva, D.; Serra-Majem, L. The Mediterranean Diet in Spain: Adherence Trends during the Past Two Decades Using the Mediterranean Adequacy Index. Public Health Nutr. 2011, 14, 622-628. [CrossRef] [PubMed]

48. García Cabrera, S.; Herrera Fernández, N.; Rodríguez Hernández, C.; Nissensohn, M.; Román-Viñas, B.; Serra-Majem, L. KIDMED Test; Prevalence of Low Adherence to the Mediterranean Diet in Children and Young: A Systematic Review. Nutr. Hosp. 2015, 32, 2390-2399. [CrossRef]

49. Riccardi, G.; Vitale, M.; Vaccaro, O. Are Europeans Moving towards Dietary Habits More Suitable for Reducing Cardiovascular Disease Risk? Nutr. Metab. Cardiovasc. Dis. 2020, 30, 1857-1860. [CrossRef] [PubMed]

50. Calderon, R.; Pupanead, S.; Prachakul, W.; Kim, G. Happiness, Perceived Stress, Psychological Well-Being, and Health Behaviors of Thai University Students: Preliminary Results from a Multinational Study on Well-Being. J. Am. Coll. Health 2021, 69, 176-184. [CrossRef] [PubMed]

51. Quehl, R.; Haines, J.; Lewis, S.P.; Buchholz, A.C. Food and Mood: Diet Quality Is Inversely Associated with Depressive Symptoms in Female University Students. Can. J. Diet. Pract. Res. 2017, 78, 124-128. [CrossRef]

52. Delicado-Soria, A.; Serrano-Urrea, R.; Cervera-Burriel, F.; Daouas, T.; García-Meseguer, M.-J. Food Consumption in Tunisian University Students and Its Association with Sociodemographic Characteristics and Lifestyle Behaviours. Public Health Nutr. 2020, 24, 4949-4964. [CrossRef]

53. Cervera Burriel, F.; Serrano Urrea, R.; Daouas, T.; Delicado Soria, A.; García Meseguer, M.J. Food habits and nutritional assessment in a tunisian university population. Nutr. Hosp. 2014, 30, 1350-1358. [CrossRef] [PubMed]

54. García-Meseguer, M.J.; Burriel, F.C.; García, C.V.; Serrano-Urrea, R. Adherence to Mediterranean Diet in a Spanish University Population. Appetite 2014, 78, 156-164. [CrossRef]

55. Ejeda-Manzanera, J.M.; Rodrigo-Vega, M. Hábitos de alimentación y calidad de dieta en estudiantes universitarias de magisterio en relación a su adherencia a la dieta mediterránea. Rev. Española Salud Pública 2021, 95, e1-e14.

56. Salas, R.; del Mar Bibiloni, M.; Zapata, M.E.; Coll, J.L.; Pons, A.; Tur, J.A. Balearic Adults Have Low Intakes of Fruits and Vegetables Compared with the Dietary Guidelines for Adults in Spain. Nutr. Res. 2013, 33, 204-210. [CrossRef]

57. Beaudry, K.M.; Ludwa, I.A.; Thomas, A.M.; Ward, W.E.; Falk, B.; Josse, A.R. First-Year University Is Associated with Greater Body Weight, Body Composition and Adverse Dietary Changes in Males than Females. PLoS ONE 2019, 14, e0218554. [CrossRef] [PubMed]

58. Leblanc, V.; Bégin, C.; Corneau, L.; Dodin, S.; Lemieux, S. Gender Differences in Dietary Intakes: What Is the Contribution of Motivational Variables? J. Hum. Nutr. Diet. 2015, 28, 37-46. [CrossRef] [PubMed]

59. Menozzi, D.; Sogari, G.; Mora, C. Explaining Vegetable Consumption among Young Adults: An Application of the Theory of Planned Behaviour. Nutrients 2015, 7, 7633-7650. [CrossRef] [PubMed]

60. Grzymisławska, M.; Puch, E.A.; Zawada, A.; Grzymisławski, M. Do Nutritional Behaviors Depend on Biological Sex and Cultural Gender? Adv. Clin. Exp. Med. 2020, 29, 165-172. [CrossRef]

61. Aljadani, H.M.; Patterson, A.J.; Sibbritt, D.; Collins, C.E. Diet Quality and Six-Year Risk of Overweight and Obesity among Mid-Age Australian Women Who Were Initially in the Healthy Weight Range. Health Promot. J. Austr. 2016, 27, 29-35. [CrossRef] [PubMed]

62. Aljadani, H.M.A.; Sibbritt, D.; Patterson, A.; Collins, C. The Australian Recommended Food Score Did Not Predict Weight Gain in Middle-Aged Australian Women during Six Years of Follow-Up. Aust. N. Z. J. Public Health 2013, 37, 322-328. [CrossRef]

63. El Ansari, W.; Stock, C.; Mikolajczyk, R.T. Relationships between Food Consumption and Living Arrangements among University Students in Four European Countries-A Cross-Sectional Study. Nutr. J. 2012, 11, 28. [CrossRef] [PubMed]

64. Lupi, S.; Bagordo, F.; Stefanati, A.; Grassi, T.; Piccinni, L.; Bergamini, M.; Donno, A.D. Assessment of Lifestyle and Eating Habits among Undergraduate Students in Northern Italy. Ann. Ist. Super. Sanità 2015, 51, 154-161. [CrossRef]

65. Côté, M.; Bégin, C. Review of the Experience of Weight-Based Stigmatization in Romantic Relationships. Curr. Obes. Rep. 2020, 9 , 280-287. [CrossRef]

66. van Woerden, I.; Brewis, A.; Hruschka, D.; Dunton, G.; Adams, M.A.; Bruening, M. Young Adults' BMI and Changes in Romantic Relationship Status during the First Semester of College. PLoS ONE 2020, 15, e0230806. [CrossRef] 
67. Moreno-Gómez, C.; Romaguera-Bosch, D.; Tauler-Riera, P.; Bennasar-Veny, M.; Pericas-Beltran, J.; Martinez-Andreu, S.; Aguilo-Pons, A. Clustering of Lifestyle Factors in Spanish University Students: The Relationship between Smoking, Alcohol Consumption, Physical Activity and Diet Quality. Public Health Nutr. 2012, 15, 2131-2139. [CrossRef]

68. Romaguera, D.; Tauler, P.; Bennasar, M.; Pericas, J.; Moreno, C.; Martinez, S.; Aguilo, A. Determinants and Patterns of Physical Activity Practice among Spanish University Students. J. Sports Sci. 2011, 29, 989-997. [CrossRef] [PubMed]

69. Sánchez-Ojeda, M.A.; De Luna-Bertos, E. Healthy lifestyles of the university population. Nutr. Hosp. 2015, 31, 1910-1919. [CrossRef] [PubMed]

70. Bennasar-Veny, M.; Yañez, A.M.; Pericas, J.; Ballester, L.; Fernandez-Dominguez, J.C.; Tauler, P.; Aguilo, A. Cluster Analysis of Health-Related Lifestyles in University Students. Int. J. Environ. Res. Public Health 2020, 17, 1776. [CrossRef]

71. Adan, R.A.H.; van der Beek, E.M.; Buitelaar, J.K.; Cryan, J.F.; Hebebrand, J.; Higgs, S.; Schellekens, H.; Dickson, S.L. Nutritional Psychiatry: Towards Improving Mental Health by What You Eat. Eur. Neuropsychopharmacol. 2019, 29, $1321-1332$. [CrossRef]

72. Moreno-Agostino, D.; Caballero, F.F.; Martín-María, N.; Tyrovolas, S.; López-García, P.; Rodríguez-Artalejo, F.; Haro, J.M.; Ayuso-Mateos, J.L.; Miret, M. Mediterranean Diet and Wellbeing: Evidence from a Nationwide Survey. Psychol. Health 2019, 34, 321-335. [CrossRef]

73. Emerson, S.D.; Carbert, N.S. An Apple a Day: Protective Associations between Nutrition and the Mental Health of Immigrants in Canada. Soc. Psychiatry Psychiatr. Epidemiol. 2019, 54, 567-578. [CrossRef]

74. Fresán, U.; Bes-Rastrollo, M.; Segovia-Siapco, G.; Sanchez-Villegas, A.; Lahortiga, F.; de la Rosa, P.-A.; Martínez-Gonzalez, M.-A. Does the MIND Diet Decrease Depression Risk? A Comparison with Mediterranean Diet in the SUN Cohort. Eur. J. Nutr. 2019, 58, 1271-1282. [CrossRef]

75. Smith, A.D.; Warren, M.J.; Refsum, H. Chapter Six-Vitamin B12. In Advances in Food and Nutrition Research; New Research and Developments of Water-Soluble Vitamins; Eskin, N.A.M., Ed.; Academic Press: Cambridge, MA, USA, 2018; Volume 83, pp. 215-279.

76. Spaeth, A.M.; Dinges, D.F.; Goel, N. Sex and Race Differences in Caloric Intake during Sleep Restriction in Healthy Adults. Am. J. Clin. Nutr 2014, 100, 559-566. [CrossRef]

77. Fang, Z.; Spaeth, A.M.; Ma, N.; Zhu, S.; Hu, S.; Goel, N.; Detre, J.A.; Dinges, D.F.; Rao, H. Altered Salience Network Connectivity Predicts Macronutrient Intake after Sleep Deprivation. Sci. Rep. 2015, 5, 8215. [CrossRef] [PubMed]

78. Heath, G.; Roach, G.D.; Dorrian, J.; Ferguson, S.A.; Darwent, D.; Sargent, C. The Effect of Sleep Restriction on Snacking Behaviour during a Week of Simulated Shiftwork. Accid. Anal. Prev. 2012, 45, 62-67. [CrossRef]

79. Mozaffarian, N.; Heshmat, R.; Ataie-Jafari, A.; Motlagh, M.E.; Ziaodini, H.; Shafiee, G.; Taheri, M.; Mansourian, M.; Qorbani, M.; Kelishadi, R. Association of Sleep Duration and Snack Consumption in Children and Adolescents: The CASPIAN-V Study. Food Sci. Nutr. 2020, 8, 1888-1897. [CrossRef] [PubMed]

80. Martinez, S.M.; Tschann, J.M.; Butte, N.F.; Gregorich, S.E.; Penilla, C.; Flores, E.; Greenspan, L.C.; Pasch, L.A.; Deardorff, J. Short Sleep Duration Is Associated with Eating More Carbohydrates and Less Dietary Fat in Mexican American Children. Sleep 2017, 40, zsw057. [CrossRef] [PubMed]

81. Nedeltcheva, A.V.; Kilkus, J.M.; Imperial, J.; Kasza, K.; Schoeller, D.A.; Penev, P.D. Sleep Curtailment Is Accompanied by Increased Intake of Calories from Snacks. Am. J. Clin. Nutr. 2009, 89, 126-133. [CrossRef]

82. Stern, J.H.; Grant, A.S.; Thomson, C.A.; Tinker, L.; Hale, L.; Brennan, K.M.; Woods, N.F.; Chen, Z. Short Sleep Duration Is Associated with Decreased Serum Leptin, Increased Energy Intake and Decreased Diet Quality in Postmenopausal Women. Obesity 2014, 22, E55-E61. [CrossRef]

83. Haghighatdoost, F.; Karimi, G.; Esmaillzadeh, A.; Azadbakht, L. Sleep Deprivation Is Associated with Lower Diet Quality Indices and Higher Rate of General and Central Obesity among Young Female Students in Iran. Nutrition 2012, 28, 1146-1150. [CrossRef]

84. Dashti, H.S.; Scheer, F.A.; Jacques, P.F.; Lamon-Fava, S.; Ordovás, J.M. Short Sleep Duration and Dietary Intake: Epidemiologic Evidence, Mechanisms, and Health Implications. Adv. Nutr. 2015, 6, 648-659. [CrossRef]

85. Binks, H.E.; Vincent, G.; Gupta, C.; Irwin, C.; Khalesi, S. Effects of Diet on Sleep: A Narrative Review. Nutrients 2020, 12, 936. [CrossRef]

86. King, B.M.; Cespedes, V.M.; Burden, G.K.; Brady, S.K.; Clement, L.R.; Abbott, E.M.; Baughman, K.S.; Joyner, S.E.; Clark, M.M.; Pury, C.L.S. Extreme Under-Reporting of Body Weight by Young Adults with Obesity: Relation to Social Desirability. Obes. Sci. Pract. 2018, 4, 129-133. [CrossRef]

87. Burke, M.A.; Carman, K.G. You Can Be Too Thin (but Not Too Tall): Social Desirability Bias in Self-Reports of Weight and Height. Econ. Hum. Biol. 2017, 27, 198-222. [CrossRef]

88. Mattioli, A.V.; Sciomer, S.; Cocchi, C.; Maffei, S.; Gallina, S. Quarantine during COVID-19 Outbreak: Changes in Diet and Physical Activity Increase the Risk of Cardiovascular Disease. Nutr. Metab. Cardiovasc. Dis. 2020, 30, 1409-1417. [CrossRef]

89. Izzo, L.; Santonastaso, A.; Cotticelli, G.; Federico, A.; Pacifico, S.; Castaldo, L.; Colao, A.; Ritieni, A. An Italian Survey on Dietary Habits and Changes during the COVID-19 Lockdown. Nutrients 2021, 13, 1197. [CrossRef] [PubMed]

90. Ferrante, G.; Camussi, E.; Piccinelli, C.; Senore, C.; Armaroli, P.; Ortale, A.; Garena, F.; Giordano, L. Did Social Isolation during the SARS-CoV-2 Epidemic Have an Impact on the Lifestyles of Citizens? Epidemiol. Prev. 2020, 44, 353-362. [CrossRef]

91. Sidor, A.; Rzymski, P. Dietary Choices and Habits during COVID-19 Lockdown: Experience from Poland. Nutrients 2020, $12,1657$. [CrossRef] [PubMed] 
92. Alegria-Lertxundi, I.; Rocandio, A.M.; Telletxea, S.; Rincón, E.; Arroyo-Izaga, M. Relación Entre El Índice de Consumo de Pescado y Carne y La Adecuación y Calidad de La Dieta En Mujeres Jóvenes Universitarias. Nutr. Hosp. 2014, 30, 1135-1143. [CrossRef] [PubMed]

93. Rodríguez-Rodríguez, E.; López-Sobaler, A.M.; Ortega, R.M.; Delgado-Losada, M.L.; López-Parra, A.M.; Aparicio, A. Association between Neutrophil-to-Lymphocyte Ratio with Abdominal Obesity and Healthy Eating Index in a Representative Older Spanish Population. Nutrients 2020, 12, 855. [CrossRef] [PubMed]

94. Weinstein, S.J.; Vogt, T.M.; Gerrior, S.A. Healthy Eating Index Scores Are Associated with Blood Nutrient Concentrations in the Third National Health and Nutrition Examination Survey. J. Am. Diet. Assoc. 2004, 104, 576-584. [CrossRef] [PubMed]

95. Fallaize, R.; Livingstone, K.M.; Celis-Morales, C.; Macready, A.L.; San-Cristobal, R.; Navas-Carretero, S.; Marsaux, C.F.M.; O’Donovan, C.B.; Kolossa, S.; Moschonis, G.; et al. Association between Diet-Quality Scores, Adiposity, Total Cholesterol and Markers of Nutritional Status in European Adults: Findings from the Food4Me Study. Nutrients 2018, 10, 49. [CrossRef] [PubMed] 